\title{
Systematically and Fast Processing Fault on Power Distribution Grids Based on a Simplified Model Part II: Advanced Approaches
}

\author{
Yusheng Zhang ${ }^{1}$, Jian Xue ${ }^{1}$ and Zhihua Zhang ${ }^{1,2, *}$ \\ ${ }^{1}$ Electric Power Research Institute, State Grid Shaanxi Electric Power Company, Xi'an 710050, China \\ ${ }^{2}$ Institude of Water Resources and Hydro-electric Engineering, Xi'an University of Technology, Xi'an 710048, China \\ ${ }^{*}$ Corresponding author
}

\begin{abstract}
This is Part II of a two-part paper which presents a methodology for fault location and isolation and service restoration (FLISR) for power distribution grids. The Criterion 1 discussed in Part $I$ is adapted to locate faults when distributed generations (DGs) exist. For DGs with larger capacity, faults can be located by coordinating the reclosing of circuit-breakers and cutting off DGs. Two advanced schemes for service restoration are presented. The modeled service restoration has priority. The service restoration with minimum load shedding assures a solution if the other three schemes fail. An algorithm of switching sequence to minimize the interruption cost is proposed. The proposed approaches to FILSR have been imbedded in 26 power distribution automation systems of $10 \mathrm{kV}$ grids since 2013, and have been proven to be a great success.
\end{abstract}

Keywords-distributed power generation; distribution networks; fault location; load flow analysis; power distribution faults; power system restoration

\section{INTRODUCTION}

More than eighty-five percent of outages in power distribution grids are caused by various faults [1]. Therefore, fast and effective fault location, isolation, and service restoration (FLISR) is of great importance to improve the service reliability.

A large amount of literature have been published on fault location. Based on the states of the fault information used, fault location methods can be divided into two types, namely, steady-state methods which utilize steady-state voltages and/or currents or the fundamental frequency components extracted from the transient signals [2], and transient methods which utilize the fault-originated electromagnetic transients of voltages and/or currents. The most common steady-state methods are based on impedance, while some transient methods are based on traveling waves [3], [4]. Impedancebased methods and traveling-wave methods are outlined in an IEEE standard [5].

Fault location methods base on impedance have been a hot topic of intense research. Impedance is calculated at power frequency [6], [7], or at a higher frequency [2]. Voltages and currents are usually measured only at the buses of substations and/or distributed-generation units [8]-[10]. In recent years smart meters have been exploited to provide more fault information [11]-[13].

Some transient methods use voltages and currents to produce energy. Energy flow and peak instantaneous power are calculated to determine on which side of a recording device a disturbance originates [14]. In [15] energy is computed for each of the guessed fault locations, and the one with the maximum value is regarded as the real fault location.

Service restoration is a constrained non-differential multiobjective optimization problem, and also is a NP-complete problem [16]. Therefore, it is the hardest stage of fault processing.

Various mathematical tools are involved for FLISR, such as neural networks [17],[18] fuzzy logic [18]-[22], particle swarm optimization [23], learning algorithm [19],[24], genetic algorithm [25]-[27], simulated annealing [16], wavelet transformation [3], [4], [17], [18], and immune algorithm [17]. Still some researchers design their own search methods [28], [29]. Uncertainty of loads and incomplete information are taken into account in [21] and [22] respectively. Load priority [28] and thermal limit [30] are included in constraints. Switching sequence [31], [32], capacitor control [31], and duration of restoration [32] are also important issues.

Most approaches for network reconfiguration assume that the distribution system is balanced, whereas unbalanced systems are studied in [6] and [33].The introduction of Distribution generations (DGs) increases not only the complexity of grids, but also the degree of difficulty of FLISR [8], [9], [26], [33], [34].

Anyway, few works of literature have dealt with the whole process of FLISR. This paper presents a methodology for FLISR on power distribution grids which are equipped with centralized automation systems. A distinguishing feature of the proposed methodology is that it is based on a simplified grid model. Load flow calculation, fault location, and network reconfiguration are carried out within a connected sub-grid which is made up of regions and which is of a far much smaller scale compared with the whole grid. The load flow is calculated through basic arithmetic operations rather than conventional complicated circuit analysis. The faulted region is located by checking the directions of the fault current or power at each region. The proposed methodology can be used 
in a grid of any scale, however large it is. Tabu search is applied to seek for a close-to-optimal service restoration solution. The algorithm for the methodology has been imbedded in the master stations of some distribution automation systems. After a fault has been detected, the whole procedure of fault processing, namely fault location, fault isolation, and service restoration is carried out automatically in sequence within a quite short time if the switches are remotely controlled.

This paper consists of two parts. Part I has presented basic concepts and simple schemes for FLISR. Part II, i.e. this part, deals with advanced approaches.

\section{FAULT LOCATION FOR DISTRIBUTION GRIDS WITH DGS}

DGs have influence on fault location, since they may not only change the amplitude of the fault current but also the direction and/or pattern of the fault power flow. They make a distribution grid like a radial grid in some cases, but a closedloop grid in other cases.

The extent of influence varies with DG types. The machine type DGs with large rated power have remarkable influence while the inverter type DGs seldom cause problems.

The positions of DGs also affect fault location. DGs attached on a feeder have some influence. While DGs directly attached to buses usually have little influence, which will not be discussed in the text.

The short-circuit capacity of the main source also affects the fault location.

The fault location criteria described in part I are called traditional fault location approaches which apply to distribution grids without DGs. But they are still suitable for fault location in most cases with DGs.

\section{A. The Influence of DGs on Traditional Fault Location Approaches}

For a closed-loop distribution grid with DGs attached on feeders, the DGs have no influence on fault location according to Criterion 2, which has been introduced in Part I. This situation will not be discussed here. If the grid operates in an open-loop mode, however, it can be treated as a radial grid.

When a fault occurs, the fault current, denoted by $I$, consists of two components. The component contributed by the main source, $I_{s}$, flows into the enter terminal of the faulted region. The other component contributed by the DGs, $I_{D G}$, flows into some out terminals of the faulted region.

If $I_{s}>>I_{D G}$, Criterion 1 or Criterion 3 , which has been introduced in Part I, can be still effective by setting a threshold current $I_{\text {set }}$. Only when $I>I_{\text {set }}$, do the feeder terminal units (FTUs) report a fault to the master station of the distribution automation system. To set $I_{\text {set }}$ properly, the worst condition should be studied first.

\section{B. The Worst Condition}

The worst condition is the one that produces the minimum fault current. It emerges when a two-phase short-circuit occurs on the furthest point of the grid away from the substation.

Suppose none of the DGs is connected to the grid. A threephase short-current happens at the furthest point of the grid produces a fault current

$$
I_{s, 3 p}=\frac{E_{s}}{Z_{s}+Z_{l 0} l}=\frac{E_{s}}{E_{s}^{2} / S+Z_{l 0} l}
$$

where

$I_{s, 3 p}$ is the three-phase short-circuit current,

$E_{s}$ is the voltage of the equivalent Thevenin source when looked into the grid,

$Z_{s}$ is the impedance of the equivalent Thevenin source,

$S$ is the short-circuit capacity of the grid, and $S=E_{s} Z_{s}$,

$Z_{l 0}$ is the per-unit length impedance of the feeder, and

$l$ is the length between the bus of the substation of the main source to the furthest point.

Then the two-phase short-circuit current Is,2p is roughly

$$
I_{s, 2 p}=0.5 \sqrt{3} I_{s, 3 p}
$$

When all of the DGs are connected, the fault current is

$$
I=0.5 \sqrt{3} I_{s, 3 p}-I_{D G}
$$

Is,2p would be the minimum at the main source node if all the DGs are connected at this node. This is, of course, unpractical, but the assumption is useful for an estimation of the minimum fault current.

\section{Maintaining The Effective Range of Criterion 1}

1) Distribution Grids with only Inverter-Type DGs: Suppose that the rated current of a feeder is $I_{\mathrm{C}}$, and that the ratio between the sum of the rated current of all the DGs and $I_{\mathrm{C}}$ is $\gamma$. Since the maximum fault current from an inverter-type DG is not more than 1.5 times of its rated current, hence under the worst conditions we have

$$
I_{D G}=1.5 \gamma_{C}
$$

Set the aforementioned threshold as

$$
I_{\text {set }}=k I_{D G}
$$

where $\mathrm{k}$ is a safety factor. Usually $\mathrm{k}=2$ is safe enough. That

$$
I_{\text {set }}=2 I_{D G}=3 \gamma I_{C}
$$

Thus, Criterion 1 is effective for a grid with DGs when 


$$
0.5 \sqrt{3} I_{s, 3 p}-I_{D G}>3 \gamma I_{C}
$$

Substituting (1) and (4) in (6) yields

$$
\frac{E_{s}}{E_{s}^{2} / S+Z_{10}}>3 \sqrt{3} \gamma I_{C}
$$

Solving it for l, we get

$$
l<\left(\frac{E_{s}}{3 \sqrt{3} \gamma I_{C}}-\frac{E_{s}^{2}}{S}\right) \frac{1}{Z_{10}}
$$

In practice, $E s=10 \mathrm{kV}$ is sufficiently accurate for $10 \mathrm{kV}$ grids. For a certain type of overhead line or cable, Zl0 and IC are known. With $S$ and $\gamma$ given, the load reach $\mathrm{l}$, the line length that ensures the applicability of Criterion 1, can be calculated by using (8).

Some values of 1 for grids with only inverter-type DGs are listed in TABLE I in the case of $\gamma=25 \%$. Only commonly used overhead line types and cable types are selected.

\begin{tabular}{|c|c|c|c|c|c|}
\hline & \multirow[t]{2}{*}{ Type } & \multirow[t]{2}{*}{$I_{C}(\mathrm{~A})$} & \multicolumn{3}{|c|}{$I(\mathbf{k m})$} \\
\hline & & & $\begin{array}{l}S=100 \\
(M V A)\end{array}$ & $\begin{array}{l}S=200 \\
(M V A)\end{array}$ & $\begin{array}{l}S=500 \\
(M V A)\end{array}$ \\
\hline \multirow{6}{*}{$\begin{array}{l}\text { Over- } \\
\text { head } \\
\text { line }\end{array}$} & $\begin{array}{l}\text { LGJ- } \\
95\end{array}$ & 295 & 31.0 & 31.9 & 32.4 \\
\hline & $\begin{array}{l}\text { LGJ- } \\
120\end{array}$ & 335 & 29.3 & 30.3 & 30.9 \\
\hline & $\begin{array}{l}\text { LGJ- } \\
150 \\
\end{array}$ & 391 & 26.0 & 27.1 & 27.8 \\
\hline & $\begin{array}{l}\text { LGJ- } \\
185 \\
\end{array}$ & 453 & 23.3 & 24.6 & 25.3 \\
\hline & $\begin{array}{l}\text { LGJ- } \\
240 \\
\end{array}$ & 536 & 19.8 & 21.1 & 21.9 \\
\hline & $\begin{array}{l}\text { LGJ- } \\
300\end{array}$ & 615 & 17.2 & 18.5 & 19.3 \\
\hline \multirow[t]{6}{*}{ Cable } & $\begin{array}{l}\text { YJV- } \\
95 \\
\end{array}$ & 298 & 69.4 & 70.4 & 71.0 \\
\hline & $\begin{array}{l}\text { YJV- } \\
120 \\
\end{array}$ & 341 & 72.6 & 74.1 & 74.9 \\
\hline & $\begin{array}{l}\text { YJV- } \\
150\end{array}$ & 390 & 73.3 & 75.3 & 76.5 \\
\hline & $\begin{array}{l}\text { YJV- } \\
185\end{array}$ & 444 & 73.0 & 75.7 & 77.2 \\
\hline & $\begin{array}{l}\text { YJV- } \\
240 \\
\end{array}$ & 523 & 70.6 & 74.1 & 76.2 \\
\hline & $\begin{array}{l}\text { YJV- } \\
300 \\
\end{array}$ & 610 & 64.6 & 68.8 & 71.2 \\
\hline
\end{tabular}

TABLE I. LOAD REACH TO ENSURE THE APPLICABILITY OF CRITERION 1 FOR GRIDS WITH ONLY INVERTER-TYPE DGS $(\gamma=25 \%)$

2) Distribution grids with only Machine-Type DGs: In contrast to the inverter-type DGs, the maximum fault current from a machine-type DG is not more than 10 times of its rated current. By following the same deduction procedure from (4)(8), the load reach for a grid with only machine-type DGs is

$$
l<\left(\frac{E_{s}}{20 \sqrt{3} \gamma I_{C}}-\frac{E_{s}^{2}}{S}\right) \frac{1}{Z_{10}}
$$

The values of $l$ for grids with only machine-type DGs are listed in TABLE II.

TABLE II. LOAD REACH TO ENSURE THE APPLICABILITY OF CRITERION 1 FOR GRIDS WITH ONLY MACHINE-TYPE DGS $(\gamma=25 \%)$

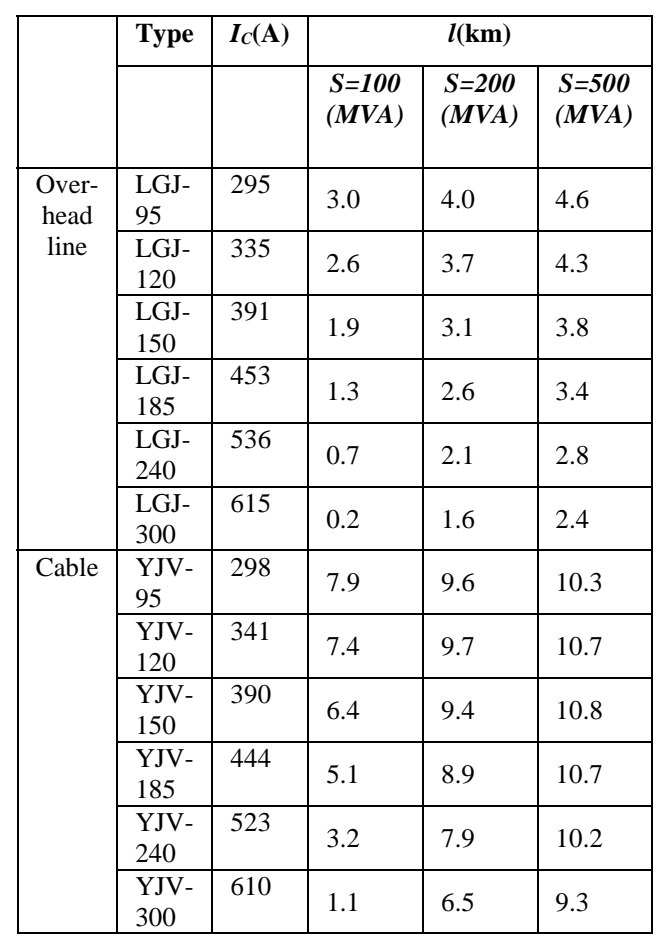

Due to the larger fault current of machine-type DGs, the load reach to ensure the applicability of Criterion 1 for grids with only machine-type DGs is much shorter than that for grids with only inverter-type DGs.

Equation (8) and (9) have been achieved by assuming extreme operation conditions. They are sufficient but not necessary conditions to ensure the applicability of Criterion 1.

3) Distribution Grids with Combined DG Types: First suppose all of the DGs are of machine type, and check by using (8) whether Criterion 1 is applicable. If not, short circuit currents have to be calculated.

An example is shown in FIGURE I. $\mathrm{S}_{1}$ and $\mathrm{S}_{2}$ are circuit breakers in substations, and they also represent the main sources. A, B, C, E and F are sectionalizors. D is a tie switch. $\mathrm{G}$ and $\mathrm{H}$ are the circuit breakers of DGs. The feeder's impedance is $Z_{10}=0.4 \Omega / \mathrm{km}$. The numbers in brackets are the lengths of the feeder sections in $\mathrm{km}$. DG $\mathrm{DG}_{1}$ is a synchronous machine, and $\mathrm{DG}_{2}$ is a double-fed induction machine. Their rated powers are both $1.25 \mathrm{MW}$. The internal reactances of $\mathrm{DG}_{1}$ and $\mathrm{DG}_{2}$ are 0.2 p.u. and 0.25 p.u., respectively. The capacities of $\mathrm{S}_{1}$ and $\mathrm{S}_{2}$ are 500MVA and 250MVA respectively. The grid has a $\gamma=12.5 \%$. 


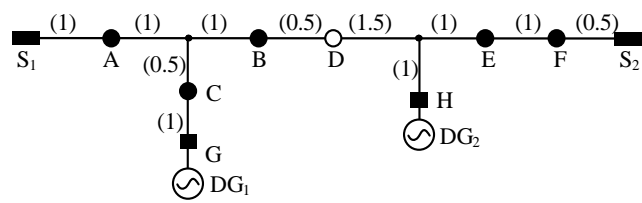

FIGURE I. A GRID WITH COMBINED DG TYPES

$\mathrm{S}_{2}$ can afford a maximum load reach $7.5 \mathrm{~km}$, which exceeds the limit that guarantees the effectiveness of Criterion 1.

If $S_{2}$ fails, $S_{1}$ will supply all the loads. At the furthest point $\mathrm{S}_{1}, I_{s, 2}=1.98 \mathrm{kA}, I_{D G}=0.82 \mathrm{kA}$.

If $S_{1}$ fails, $S_{2}$ will supply all the loads. At the furthest point $\mathrm{S}_{2}, I_{s, 2}=1.85 \mathrm{kA}, I_{D G}=0.76 \mathrm{kA}$.

Therefore, by setting $I_{\text {set }}=1.42 \mathrm{kA}$, Criterion 1 is still suitable.

\section{Fault Location for Grids with Large-Capacity DGs}

If a feeder is connected with large-capacity DGs, a threshold may not be found. A fault location method based on the coordination of reclosing is proposed here. The main points are as follows:

- The time delay for reclosing the circuit breaker is extended to $3 \mathrm{~s}$.

- At time $t=0$, a fault occurs, the certain circuit breaker is tripped.

- At $t=2 \mathrm{~s}$, all of the DGs on the feeder are cut out by the anti-islanding protection.

- At $t=3 \mathrm{~s}$, the tripped circuit breaker is reclosed. If the fault is temporary, the service is restored and the DGs will be connected soon. If it is permanent, the reclosing results in a fault which produces the same fault phenomenon as without DGs. The fault, therefore, can be located by traditional approaches no matter how large the capacity of the DGs are.

\section{SERVICE RESTORATION With Minimum LOAD SHEDDING}

One of the constraints for the short/real time service restoration scheme is no load shedding. But in some cases such as bus voltage losses, loads have to be shed, and the two schemes are not able to figure out any service restoration solution. Then comes the service restoration with minimum load shedding. This often involves several connected sub-grids.

The objectives are to

- Maximize Load Balance Degree

- Minimize load shedding

- Maximize the load restored with fewer switching operations

The constraints are

- No overload

- Current limits of nodes
- Grid topology

- no loops among main source nodes

- Controllability of nodes

The constraint of grid topology has two aspects. Only one of them, i.e. no loops among main source nodes, is suitable for the service restoration with minimum load shedding.

\section{A. Tabu Search}

The algorithms of Tabu search for real- and short- time service restoration do not support load shedding due to overload, because the number of the open action nodes is constant for each feasible restoration scheme.

To solve this problem, the virtual open action node (VOAN) is introduced. A VOAN is located next to a main source node or overlaps an ending node, as shown in FIGURE II. During one iteration of the search process, one of the VOANs or the tie switch moves to and replaces its neighboring action node, which forms a new candidate solution. Some of the candidates are shown in FIGURE III.

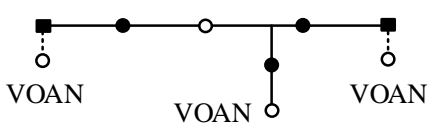

\section{FIGURE II. INITIAL POSITIONS OF VIRTUAL OPEN ACTION NODES (VOANs)}

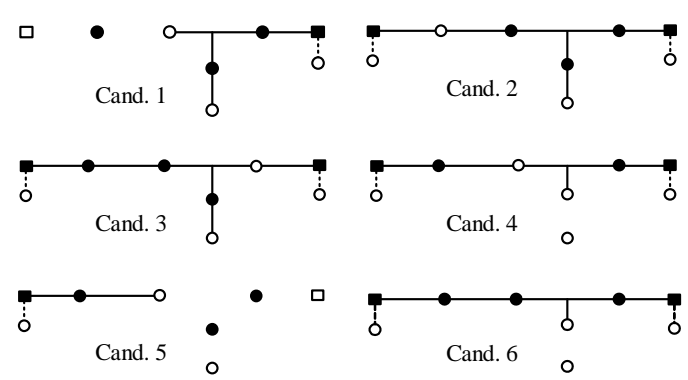

FIGURE III. CANDIDATE SOLUTIONS FOR THE GRID IN FIGURE II

The VOANs for candidates 2 and 3 are at their initial positions, which means that all loads are restored without any load shedding. Candidates 1,4 , and 5 are cases with load shedding. Candidate 6 is not feasible since the two main source nodes are looped.

\section{B. Service Restoration with Minimum Load Shedding}

Large-area power outage may occur in the case of bus voltage losses due to a fault on a bus, transformer or transmission line. The service restoration with minimum load shedding is a great help in a situation like this.

An example of large-area power outage is shown in FIGURE IV. The data in brackets are the region loads. The rated current of the transformer nodes $78,80,83,85,88$, and 90 is $1400 \mathrm{~A}$. The rated current of the other action nodes is 400A. The grid works normally with a total load 3072A. 
Suddenly both bus- 5 and bus- 6 encounter a voltage loss due to an upstream accident. The action nodes $7,18,73,74,29,52$, and 54, each of which in fact is a circuit-breaker, are tripped.

In order to restore the service by using the algorithm in the last section, the action nodes to be opened are nodes $6,49,53$, 66 , and 76 , and the action nodes to be closed are nodes 4,13 , 25, 27, 47, 51, 61, 71, and 72.

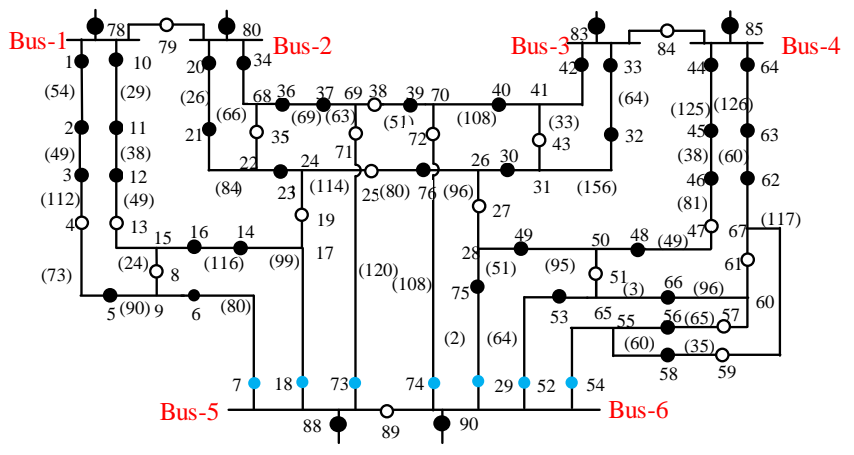

FIGURE IV. AN EXAMPLE OF SERVICE RESTORATION TO AVOID OF LARGE-AREA POWER OUTAGE

For an outage which affects a large area and many customers, some principles should be followed during the service restoration:

- Dangerous loops are not allowed. Temporary loops are permitted in some cases, such as when the related two feeders are from the same bus.

- Priority customers with political importance such as hospital are restored first, followed by loads with large economical profit.

Tabu search has found the final configurations, but has not provided a feasible switching sequence. An appropriate sequence is proposed as follows.

Step 1: Put the action nodes to be closed into set $\boldsymbol{Q}_{c}$.

Step 2: Take an action node $N_{c}$ from $\boldsymbol{Q}_{c}$. Search its upstream and downstream until a source node, or an ending node, or a to-be-opened node is met. If one or more to-beopened nodes are found, they and $N_{c}$ make an element in group 2, which is put into set $\boldsymbol{G}_{2}$. If no to-be-opened node is found, $N_{c}$ alone makes an element in group 1 , which is put into $\boldsymbol{G}_{1}$. It is clear that an element in group 1 contains only to-beclosed nodes, whereas an element in group 2 contains both tobe-opened and to-be-closed nodes.

Step 3: If $\boldsymbol{Q}_{c}$ is not empty, return to Step 2.

Step 4: Calculate the economical profit for each element in $\boldsymbol{G}_{1}$, and put them in descending order in set $\boldsymbol{W}$. For priority customers, their economical profits should be weighted to guarantee their priority over others.

Step 5: Calculate the economical profit for each element in group 2 in $\boldsymbol{G}_{2}$, and append them in descending order in $\boldsymbol{W}$. Closing operations have priority over opening operations if allowed.

Step 6: Check each operation in $\boldsymbol{W}$ from top to bottom for possible overload. If there is any overload, move this operation downwards for one pace.

Step 7: Operate the nodes in $\boldsymbol{W}$ one by one from top to bottom.

For the fault described for FIGURE IV, the groups 1 and 2 have 3 and 6 elements respectively, as shown in the columns 3 and 4 in TABLE III. The data in the right-most column are 4 hours' economical profit.

TABLE III. Node Operation Sequence and Economical Profit for Service Restoration

\begin{tabular}{|c|c|c|c|c|c|}
\hline & $\begin{array}{c}\text { Element } \\
\text { no. }\end{array}$ & $\begin{array}{l}\text { Nodes } \\
\text { to be } \\
\text { closed } \\
\end{array}$ & $\begin{array}{l}\text { Nodes } \\
\text { to be } \\
\text { opened }\end{array}$ & $\begin{array}{c}\text { Node } \\
\text { operation } \\
\text { sequence }\end{array}$ & $\begin{array}{c}4 \text { hours' } \\
\text { economical } \\
\text { profit }(\$)\end{array}$ \\
\hline \multirow{3}{*}{$\begin{array}{l}\text { Group } \\
1\end{array}$} & 1 & 13 & & Close13 & 108109.64 \\
\hline & 2 & 71 & & Close 71 & 65095.49 \\
\hline & 3 & 72 & & Close 72 & 47063.29 \\
\hline \multirow[t]{6}{*}{$\begin{array}{l}\text { Group } \\
2\end{array}$} & 4 & 4 & 6 & $\begin{array}{l}\text { Open } 6 \\
\text { Close } 4\end{array}$ & 88421.37 \\
\hline & 5 & 47 & 49 & $\begin{array}{l}\text { Open } 49 \\
\text { Close } 47\end{array}$ & 67265.34 \\
\hline & 6 & 61 & 66 & $\begin{array}{l}\text { Open } 66 \\
\text { Close } 61\end{array}$ & 41834.03 \\
\hline & 7 & 51 & $49,53,66$ & \begin{tabular}{|l|} 
Open 53 \\
Close 51 \\
\end{tabular} & 255.33 \\
\hline & 8 & 25 & 76 & $\begin{array}{l}\text { Open } 76 \\
\text { Close } 25 \\
\end{array}$ & 0 \\
\hline & 9 & 27 & 49,76 & Close 27 & -4518.96 \\
\hline
\end{tabular}

For elements 1 to 3, close the nodes one by one. For elements 4, 5, 6, and 8, first open one node and then close the other. For element 7, first open node 53 and then close node 51. Nodes 49 and 66 have already been opened during the previous operations. For element 9 , the only node to be operated is node 27 for the same reason.

\section{MODELED SERVICE RESTORATION}

Some power distribution grids possess modeled configurations which have been specially designed. In this section, service restoration schemes for multi-section multilink grids, and grids with multi-main and one backup sources will be described. Service restoration for these kinds of modeled grids does not need complicated searching and calculating process as mentioned above, because no load is shed and the constraints in Part I are all satisfied. Service restoration for modeled grids is modeled too.

\section{A. Multi-Section Multi-Link Grids}

A multi-Section multi-link grid, also named an m-section m-link grid, possesses following characteristics:

- A feeder is divided into m feeder sections with uniformly distributed load along the feeder.

- Each feeder section is connected with a different feeder. None two of the feeders connected to the same feeder section.

- The rated current of each feeder is the same. 
A 2-section 2-link grid comprises at least three feeders as shown in FIGURE V(A). Another typical 2-section 2-link grid is shown in FIGURE V(B).

A 3-section 3-linked grid comprises at least four feeders which is shown in FIGURE VI(A). Another typical 3-section 3-link grid is shown in FIGURE VI(B).
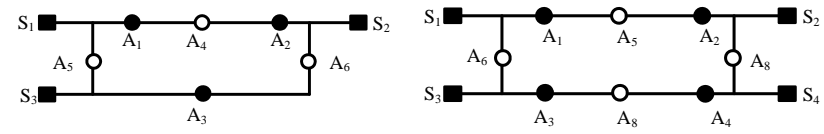

FIGURE V. TYPICAL 2-SECTION 2-LINK GRIDS: (A) A 2SECTION 2-LINK GRID WITH THREE FEEDERS. (B) A 2-SECTION 2LINK GRID WITH FOUR FEEDERS
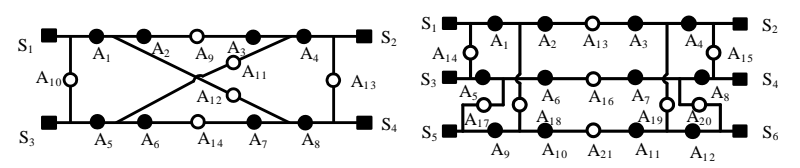

FIGURE VI. TYPICAL 3-SECTION 3-LINK GRIDS: (A) A 3SECTION 3-LINK GRID WITH FOUR FEEDERS. (B) A 3-SECTION 3LINK GRID WITH FOUR FEEDERS

The modeled service restoration scheme for a 3-section 3link grid is demonstrated in FIGURE VII. The feeder with the main source node $S_{1}$ is divided into three feeder sections by the action nodes $\mathrm{A}$ and $\mathrm{B}$. The three feeder sections are connected through the action nodes $\mathrm{C}, \mathrm{D}$ and $\mathrm{E}$ to other three feeders, whose main source nodes are $S_{2}, S_{3}$ and $S_{4}$, respectively.

If a fault occurs in the region $\operatorname{Re}(\mathrm{B}, \mathrm{C})$ as shown in FIGURE VII (B), $\operatorname{Re}\left(\mathrm{S}_{1}, \mathrm{~A}, \mathrm{D}\right)$ and $\operatorname{Re}(\mathrm{A}, \mathrm{B}, \mathrm{E})$ are restored by $S_{1}$.

If a fault occurs in $\operatorname{Re}(\mathrm{A}, \mathrm{B}, \mathrm{E})$ as shown in FIGURE VII (C), $\operatorname{Re}\left(\mathrm{S}_{1}, \mathrm{~A}, \mathrm{D}\right)$ is restored by $\mathrm{S}_{1}$, and $\operatorname{Re}(\mathrm{B}, \mathrm{C})$ is restored by $\mathrm{S}_{2}$.

If a fault occurs in $\operatorname{Re}\left(\mathrm{S}_{1}, \mathrm{~A}, \mathrm{D}\right)$ as shown in FIGURE VII (D), $\operatorname{Re}(\mathrm{A}, \mathrm{B}, \mathrm{E})$ is restored by $\mathrm{S}_{4}$ and $\operatorname{Re}(\mathrm{B}, \mathrm{C})$ is restored by $\mathrm{S}_{2}$.

In case of $\mathrm{S}_{1}$ failure as shown in FIGURE VII $(\mathrm{E}), \operatorname{Re}\left(\mathrm{S}_{1}\right.$, $A, D)$ is restored by $S_{3}, \operatorname{Re}(A, B, E)$ is restored by $S_{4}$ and $\operatorname{Re}(B$, C) is restored by $S_{2}$.

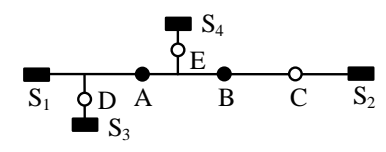

(A)

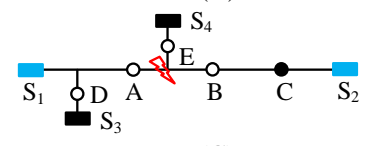

(C)

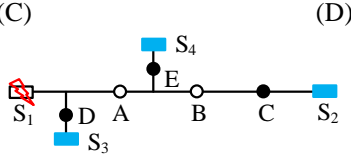

(E)

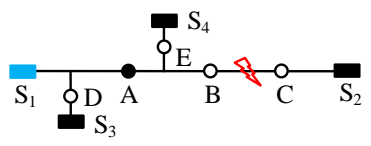

(B)

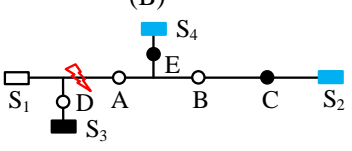

(D)
FIGURE VII. MODELED SERVICE RESTORATION SCHEME FOR A 3-SECTION 3-LINK GRID: (A) NORMAL OPERATION. (B) RE (B, C) IS FAULTED. (C) RE (A, B, E) IS FAULTED. (D) RE (S1, A, D) IS FAULTED. (E) S1 FAILS

\section{B. Grids with Multi-Main and One Backup Sources}

The characteristics of a grid with multi-main and one backup sources (m-main and 1 backup sources) are as the follows:

- Several feeders are connected to one bus.

- One of the feeders is on standby while the other feeders carry loads during normal operation.

- The rated current of each feeder is the same.

A grid with 2-main and 1 backup sources is used as an example to demonstrate the modeled service restoration scheme, as shown in FIGURE VIII.

Whenever any fault occurs on one of the load-carrying feeders, the backup feeder will supply power to the downstream of the fault region, while the main source will supply power to the upstream.

(a) A fault occurs in $\operatorname{Re}\left(A_{4}, A_{5}\right)$. The main source node $S_{1}$ is tripped to clear the fault current.

(b) Action nodes $A_{4}$ and $A_{5}$ are opened to isolate the faulted region.

(c) $S_{1}$ is closed to restore the upstream of the faulted region.

(d) Action nodes $A_{7}$ is closed to restore the downstream of the faulted region.

The downstream of the fault can also be restored by the main source $S_{2}$ if the load is light.

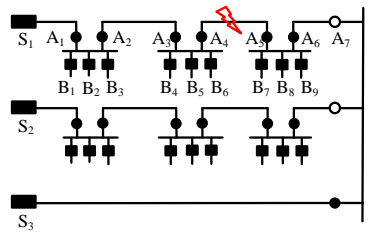

(A)

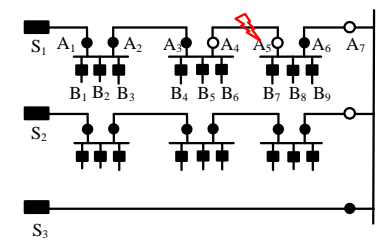

(B) 


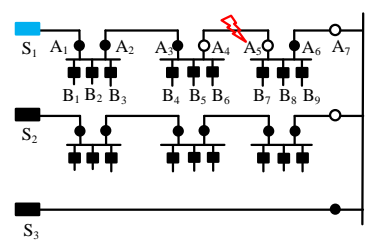

(C)

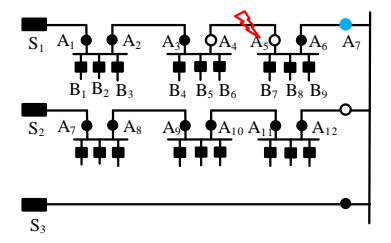

(D)
FIGURE VIII. THE MODELED SERVICE RESTORATION SCHEME FOR A GRID OF THREE-MAIN AND ONE SOURCES. (A) A FAULT OCCURS. (B) THE FAULT IS ISOLATED. (C) THE UPETREAM IS RESTORED. (D) THE DOWNSTREAM IS RESTORED

\section{COORDinAtion OF THE Four Types OF SERVICE RESTORATION}

Two parts of this paper have presented all together four service restoration schemes: the real time service restoration, the short time service restoration, the service restoration with minimum load shedding, and the modeled service restoration. The usage coordination of the schemes is shown in the flowchart in FIGURE IX.

For a faulted grid with modeled configuration, the modeled service restoration is tried first. If any operation of the action nodes fails, or the grid is not a modeled one, forecast the load for the near future, for example for a period of 4-6 hours, and use the short time service restoration scheme. If the forecast is not available or the scheme fails, try the real time service restoration scheme. If the real time scheme fails again, use the minimum load shedding scheme, which will certainly succeed.

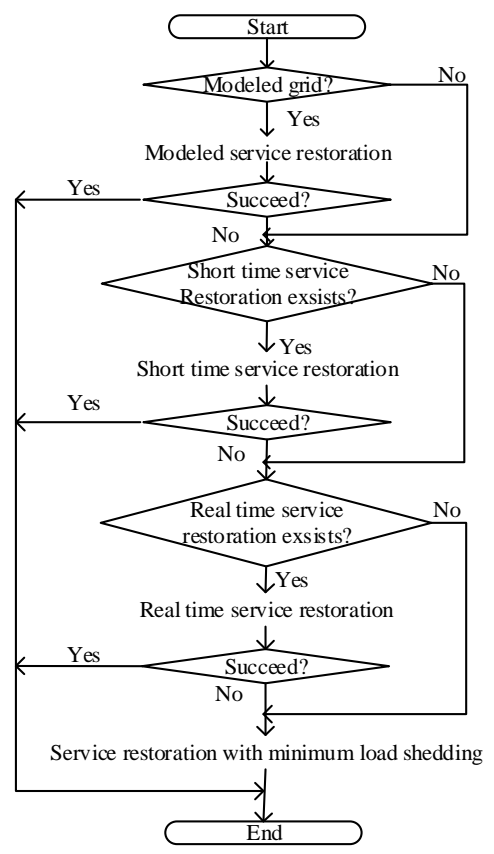

FIGURE IX. COORDINATION OF THE FOUR SERVICE RESTORATION SCHEMES

\section{ENGINEERING APPLICATION}

The proposed methods of FLISR have been imbedded in 26 power distribution automation systems since 2013, including cities such as Xian, Hangzhou, and Nanjing. The master stations can work out the solution for FLISR in the order of seconds and even shorter. The whole fault processing time, varying according to the numbers of the nodes in the grids, is significantly reduced to in the order of minutes from hours when faults were handled by human hands before. Most of the time is spent on the interaction of the communication system. The proposed methods have been proven to be a great success.

\section{CONCLUSIONS}

This is Part II of a two-part paper which presents systematical and fast approaches to FLISR on power distribution grids. Part I has introduced basic concepts and schemes. Part II has discussed advanced approaches.

The traditional fault location approaches have been adapted to solve problems on distribution grids with DGs. With the worst condition being taken into account, Criterion 1 for locating faults on a radial distribution grid is still effective for grids with DGs by setting an appropriate threshold. When DGs with large capacity are connected, faults can be located by coordinating the reclosing of circuit-breakers and cutting off DGs.

Four service restoration schemes have been suggested. The first two have been introduced in Part I, and the other two in this Part II. When a fault occurs, the modeled service restoration has priority over the other three schemes. If it fails, the short time service restoration, and the real time service restoration are tried. If they fail too, the service restoration with minimum load shedding assures a solution.

The proposed approaches have been imbedded in 26 power distribution automation systems of $10 \mathrm{kV}$ grids since 2013, and have been proven to be a great success.

\section{ACKNOWLEDGEMENTS}

Yusheng Zhang received the B.Sc. degree in electrical engineering from Kunming University of Science and Technology, Kunming, Yunnan Province, China, in 2008. In 2008, he joined Shaanxi Electric Power Research Institute. His main research interests are in power distribution system analysis and protection, fault detection and location, and distributed generation.

Jian Xue received the B.Sc. degree in electrical engineering from North China Electric Power University, Beijing, China, in 2002. In 2002, he joined Shaanxi Electric Power Research Institute. His main interests include power distribution system, protection, fault detection and location.

Zhihua Zhang received the B.Sc. and M.Sc. degrees in electrical engineering from Xi'an University of Science and Technology, Xi'an, Shaanxi Province, China, in 2009 and 2012 respectively. In 2012, he joined Shaanxi Electric Power Research Institute. His main research interests are in power distribution system analysis and protection, fault detection and location, and distributed generation.

\section{REFERENCES}

[1] J. Liu, X. Dong, X. Chen, X. Tong, X. Zhang, and S. Xu, Fault Location and Service Restoration for Electrical Distribution Systems. Singapore: Wiley, 2016, pp. 89-162.

[2] K. Jia, D. Thomas and M. Sumner, "A new single-ended fault-location scheme for utilization in an integrated power system," IEEE Trans. Power Del., vol. 28, no. 1, pp. 38-46, Jan. 2013.

[3] A. Borghetti,M. Bosetti, C. A. Nucci,M. Paolone, and A. Abur, "Integrated use of time-frequency wavelet decompositions for fault 
location in distribution grids: Theory and experimental validation,” IEEE Trans. Power Del., vol. 25, no. 4, pp. 3139-3146, Oct. 2010.

[4] A. Borghetti, M. Bosetti, M. D. Silvestro, C. A. Nucci, and M. Paolone, "Continuous-wavelet transform for fault location in distribution power grids: Definition of mother wavelets inferred from fault originated transients,” IEEE Trans. Power Syst., vol. 23, no. 2, pp. 380-388, May 2008.

[5] IEEE Guide for Determining Fault Location on AC Transmission and Distribution Lines, IEEE Standard C37.114, 2014.

[6] M. S. Choi, S. J. Lee, D. S Lee, and B. G. Jin, "A new fault location algorithm using direct circuit analysis for distribution systems," IEEE Trans. Power Del., vol. 19, no. 1, pp. 35-41, Jan. 2004.

[7] M. S. Choi, S. J. Lee, S. I. Lim, D. S. Lee and X. Yang, "A direct threephase circuit analysis-based fault location for line-to-line fault," IEEE Trans. Power Del., vol. 22, no. 4, pp. 2541-2547, Oct. 2007.

[8] S. F. Alwash, V. K. Ramachandaramurthy and N. Mithulananthan, "Fault-location scheme for power distribution system with distributed generation," IEEE Trans. Power Del., vol. 30, no. 3, pp. 1187-1195, June 2015.

[9] S. M. Brahma, "Fault location in power distribution system with penetration of distributed generation," IEEE Trans. Power Del., vol. 26, no. 3, pp. 1545-1553, July 2011.

[10] Y. Liao, "Generalized fault-location methods for overhead electric distribution systems," IEEE Trans. Power Del., vol. 26, no. 1, pp. 53-64, Jan. 2011.

[11] F. C. L. Trindade, W. Freitas and J. C. Vieira, "Fault location in distribution systems based on smart feeder meters," IEEE Trans. Power Del., vol. 29, no. 1, pp. 251-260, Feb. 2014.

[12] M. Majidi, A. Arabali and M. Etezadi-Amoli, "Fault location in distribution grids by compressive sensing," IEEE Trans. Power Del., vol. 30, no. 4, pp. 1761-1769, Aug. 2015.

[13] M. Majidi, M. Etezadi-Amoli and M. Sami Fadali, "A novel method for single and simultaneous fault location in distribution grids," IEEE Trans. Power Syst., vol. 30, no. 6, pp. 3368-3376, Nov. 2015.

[14] A. C. Parsons, W. M. Grady, E. J. Powers and J. C. Soward, "A direction finder for power quality disturbances based upon disturbance power and energy," IEEE Trans. Power Del., vol. 15, no. 3, pp. 1081-1086, Jul 2000.

[15] R. Razzaghi, G. Lugrin, H. Manesh, C. Romero, M. Paolone and F. Rachidi, "an efficient method based on the electromagnetic time reversa to locate faults in power grids," IEEE Trans. Power Del., vol. 28, no. 3, pp. 1663-1673, July 2013.

[16] S. Toune, H. Fudo, T. Genji, Y. Fukuyama, and Y. Nakanishi, "Comparative study of modern heuristic algorithms to service restoration in distribution systems,” IEEE Trans. Power Del., vol. 17, no. 1, pp. 173-181, Jan. 2002.

[17] M. Pourahmadi-Nakhli and A. A. Safavi, "Path characteristic frequencybased fault locating in radial distribution systems using wavelets and neural networks," IEEE Trans. Power Del., vol. 26, no. 2, pp. 772-781, Apr. 2011.

[18] A. A. P. Bíscaro, R. A. F. Pereira, M. Kezunovic, and J. R. S. Mantovani, "Integrated fault location and power-quality analysis in electric power distribution systems,” IEEE Trans. Power Del., vol. 31, no. 2, pp. 428436, Apr. 2016.

[19] J.Mora-Florez, V. Barrera-Nuez, and G. Carrillo-Caicedo, "Fault location in power distribution systems using a learning algorithm for multivariable data analysis,” IEEE Trans. Power Del., vol. 22, no. 3, pp. 1715-1721, Jul. 2007.

[20] Y. Y. Hsu and H. C. Kuo, "A heuristic based fuzzy reasoning approach for distribution system service restoration,” IEEE Trans. Power Del.,vol. 9, no. 2, pp. 948-953, Apr. 1994.

[21] D. S. Popovic and Z. N. Popovic, "A risk management procedure for supply restoration in distribution networks,” IEEE Trans. Power Syst., vol. 19, no. 1, pp. 221-229, Feb. 2004.

[22] W. H. Chen, "Fault section estimation using fuzzy matrix-based reasoning methods,” IEEE Trans. Power Del., vol. 26, no. 1, pp. 205213, Jan. 2011
[23] A. Shahsavari, S. M. Mazhari, A. Fereidunian and H. Lesani, "Fault indicator deployment in distribution systems considering available control and protection devices: a multi-objective formulation approach," IEEE Trans. Power Syst., vol. 29, no. 5, pp. 2359-2369, Sept. 2014.

[24] J. Mora-Florez, V. Barrera-Nunez and G. Carrillo-Caicedo, "fault location in power distribution systems using a learning algorithm for multivariable data analysis," IEEE Trans. Power Del., vol. 22, no. 3, pp. 1715-1721, July 2007.

[25] W. F. Usida, D. V. Coury, R. A. Flauzino, and I. N. da Silva, "Efficient placement of fault indicators in an actual distribution system using evolutionary computing,’IEEE Trans. Power Syst., vol. 27, no. 4, pp. 1841-1849, Nov. 2012.

[26] V. Kumar, R. H. C. Kumar, I. Gupta, and H. O. Gupta, "DG integrated approach for service restoration under cold load pickup,” IEEE Trans. Power Del., vol. 25, no. 1, pp. 398-406, Jan. 2010.

[27] Y. Kumar, B. Das, and J. Sharma, "Multiobjective, multiconstraint service restoration of electric power distribution system with priority customers,” IEEE Trans. Power Del., vol. 23, no. 1, pp. 261-270, Jan. 2008.

[28] K. N. Miu, H.-D. Chiang, B. B. Yuan, and G. Darling, "Fast service restoration for large-scale distribution systems with priority customers and constraints,” IEEE Trans. Power Syst., vol. 13, no. 3, pp. 789-795, Aug. 1997.

[29] M. R. Kleinberg, K. Miu, and H. -D. Chiang, "Improving service restoration of power distribution systems through load curtailment of inservice customers,” IEEE Trans. Power Syst., vol. 26, no. 3, pp. 1110 1116, Aug. 2011.

[30] C. Ucak and A. Pahwa, "An analytical approach for step-by-step restoration of distribution systems following extended outages,” IEEE Trans. Power Del., vol. 9, no. 3, pp. 1717-1723, Jul. 1994.

[31] K. Miu, H.-D. Chiang, and R. J. McNulty, "Multi-tier service restoration through network reconfiguration and capacitor control for large scale radial distribution systems,” IEEE Trans. Power Syst., vol. 15, no. 3, pp. 1001-1007, Aug. 2000

[32] P. Wang and W. Li, "Reliability evaluation of distribution systems considering optimal restoration sequence and variable restoration times," IET Gen., Transm., Distrib., vol. 1, no. 4, pp. 688-695, Jul. 2007.

[33] F. Ding, and K. A. Loparo, "Feeder reconfiguration for unbalanced distribution systems with distributed generation: a hierarchical decentralized approach,” IEEE Trans. Power Syst., vol. 31, no. 2, pp. 1633-1642, May 2016.

[34] T. T. H. Pham, Y. Bésanger, and N. Hadjsaid, "New challenges in power system restoration with large scale of dispersed generation insertion," IEEE Trans. Power Syst., vol. 24, no. 1, pp. 398-406, Feb. 2009. 